\title{
扫描质子探针在微量金赋存状态 研究中的应用
}

\author{
魏元柏 陈 武 周建平 \\ (南京大学地球科学系,南京 210008)
}

\author{
朱节清 谷英梅 陆荣荣 \\ (中国科学院上海原子核研究所,上海 201800)
}

\section{关键词微量金、赋存状态、扫描质子探针}

目前, 有关金的赋存状态研究, 多集中在含金量为 $100 \mathrm{ppm}$ 以上之样品, 对含金量 $<100$ $\mathrm{ppm}$ 甚至为几个 $\mathrm{ppm}$ 之样品中金的赋存状态研究相对较少, 这在很大程度上受分析检测手 段所制约. 电子探针 (EMP), 虽然分辨率较高 $(\leqslant 1 \mu \mathrm{m})$, 但检出下限为 $100 \sim 500 \mathrm{ppm}$; 扫 描电子显微镜 (SEM), 其分辨率也较高, 但扫描元素的含量也须在 $100 \sim 300 \mathrm{ppm}$ 以上; 电 子顺磁共振谱 (EPR) 是判别晶格金颇为有效的方法之一, 但顺磁离子的含量也须在几十个 $\mathrm{ppm}$ 以上. 因此, 对含金量低 $(<100 \mathrm{ppm})$ 之样品中金的赋存状态研究, 上述诸手段均无能为 力, 而新近发展起来的扫描质子探针 (SPMP), 又称核探针(Nuclear Microprobe)则具有 ppm 级的检测下限和 $0.5 \sim 1 \mu \mathrm{m}$ 的空间分辨率,为上述问题的解决,提供一个有效的分析检测手段.

我们利用中国科学院上海原子核研究所的扫描质子探针,对安徽铜陵老鸦岭铜矿床中, 伴 生金的赋存状态开展了初步的研究, 本文专题报道此初步研究结果.

\section{1 样品的制备及其实验方法}

安徽铜陵老鸦岭铜矿床中, 其伴生金的平均含量为 $0.32 \mathrm{ppm}$,大量的分析结果表明 ${ }^{1}:$ 其主 要载金矿物为黄铜矿、黄铁矿和部分石英. 对主要载金矿物, 在扫描电镜下,进行了大量的金 扫描分析,结果均不能显示金的存在,这表明: 在选区范围内, 其金的平均含量达不到扫描电 镜之检测下限, 这既可能是不可见金的颗粒远小于扫描电镜的电子束斑, 又可能是以含量极低 的晶格金存在. 为解决这个问题, 我们结合其他分析资料, 在大量光片观察之基础上, 选择了 二个最有代表性的样品,喷上碳膜,以作扫描质子探针分析用.

本次实验所用的扫描质子探针, 采用长焦距四极透镜来聚焦质子束,聚焦后束斑的空间分 辨率 $<3 \mu \mathrm{m}$, 采用快速随机的方式对有关元素进行扫描, 以各别事件的方式获取数据, 每个 事件包括由探测器接收到的每个粒子之能量信息和束斑扫描轨迹的座标信息, 然后由计算机 进行处理, 绘制成清晰直观的元素分布之等高线图及其相应的能谱图 ${ }^{[1,2]}$ (能谱图从略).

\section{2 结果和讨论}

图 1,2 为选区中质子探针扫描分析的有关元素分布之等高线图, 从图中可以看出:

1. 金主要集中分布于黄铜矿、黄铁矿及部分石英中, 且石英中之含量相对较低.

2. 金在上述三种矿物中的分布是极不均匀的, 这种不均匀性不仅表现在同一矿物的不同 颗粒上(如图 1 中的 A,B,C 区), 而且表现在同一矿物之同一颗粒内部. 在图 1 中表现为若干

1992-07-11 收稿, 1993-03-15 收修改稿.

*中国科学院核分析技术联合开放研究实验室上海分部部分资助课题.

1) 关于该矿床中金赋存状态的详细研究成果将另文发表. 


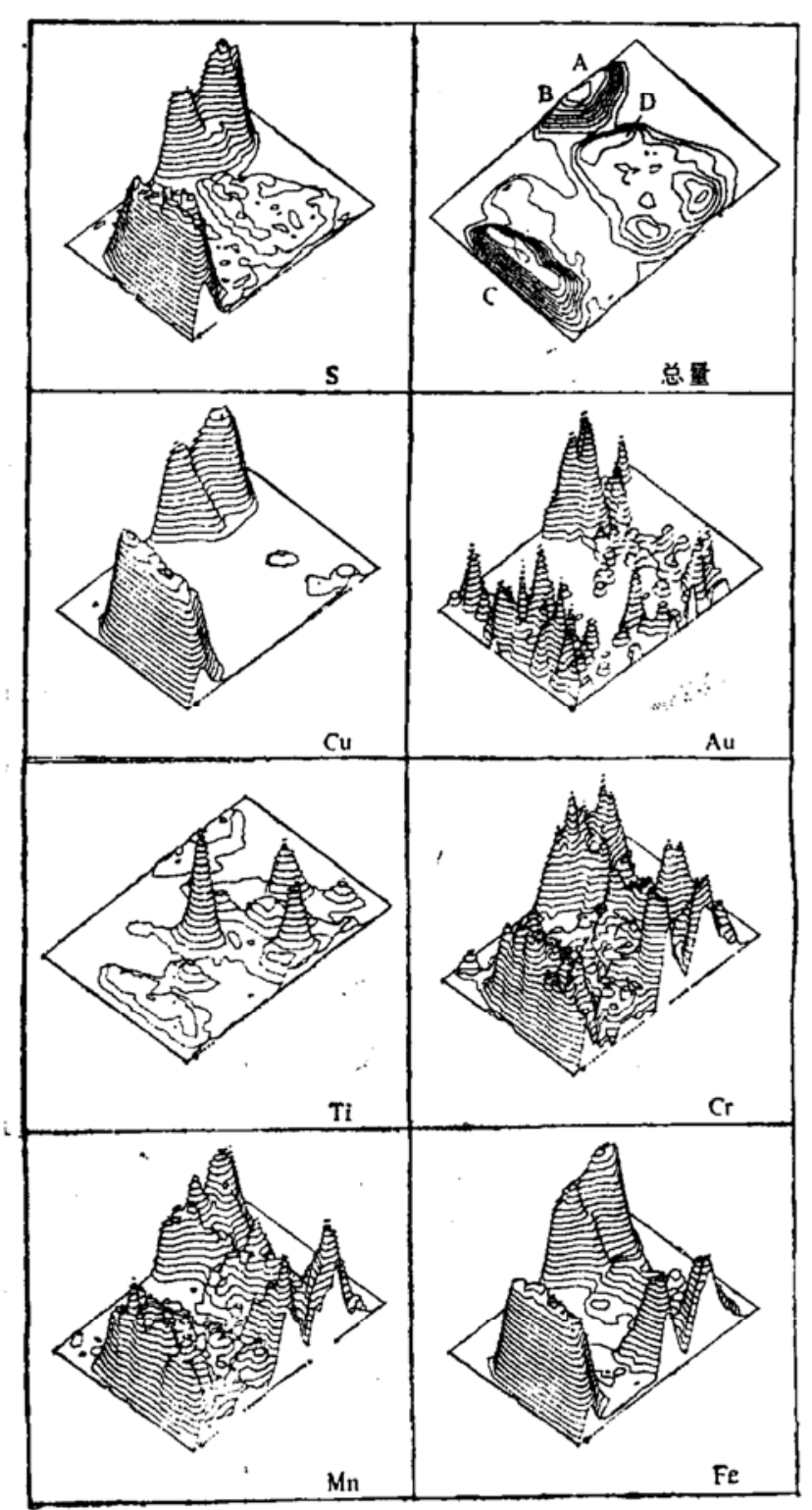

图 1 黄铜矿及石英中 $\mathrm{Au}, \mathrm{Cu}, \mathrm{Fe}$ ， $\mathrm{Ti}, \mathrm{C}_{r}, \mathrm{~S}$ 的分布图

图中右上角为相应选区的位置图: A, B,C 区为黄铜矿， D 区为石英. 扫描范围为 $154 \times 225 \mu \mathrm{m}$

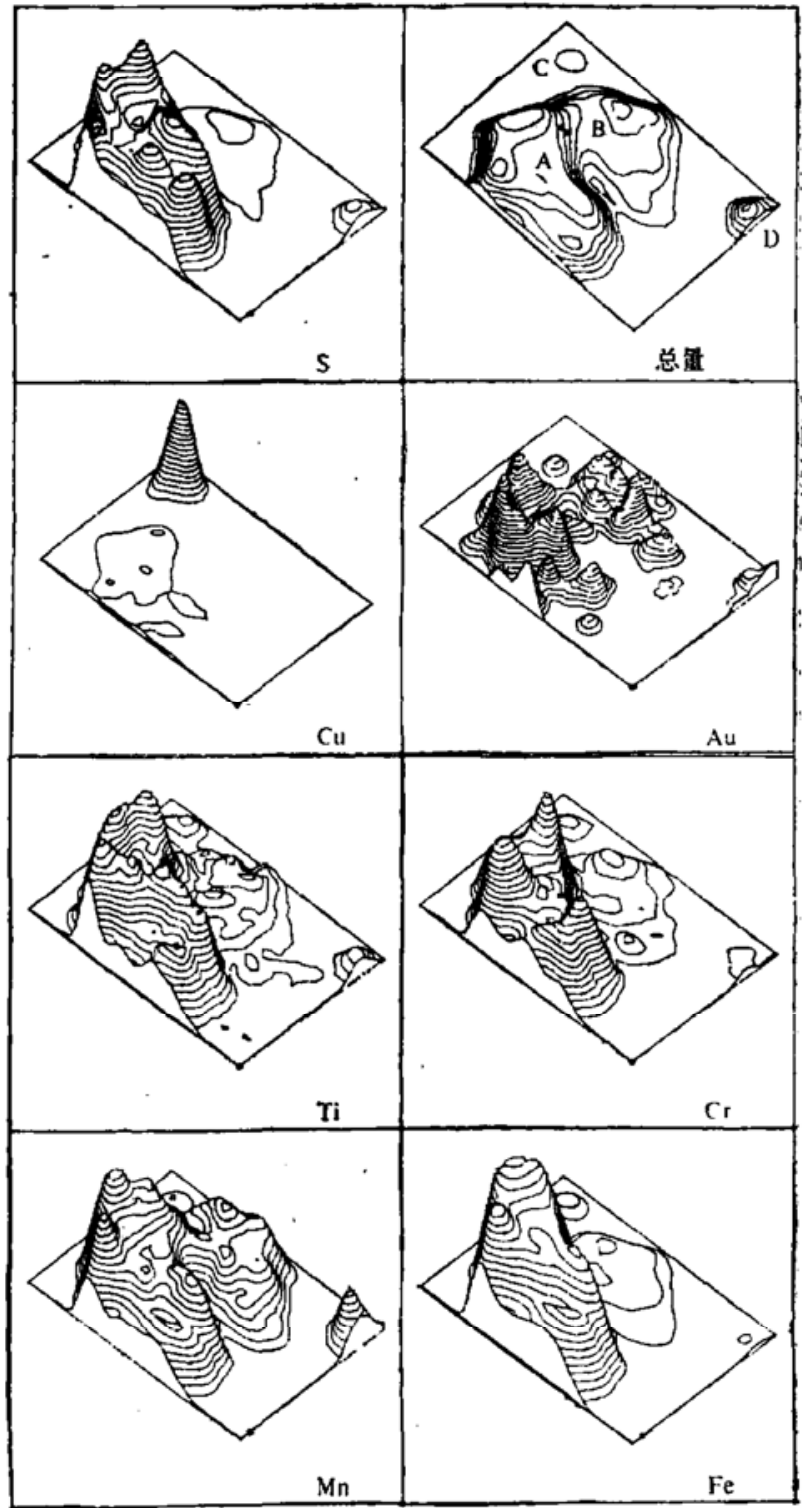

图 2 黄铁矿及石英中 $\mathrm{Au}, \mathrm{Cu}, \mathrm{Fe}, \mathrm{Ti}$, $\mathrm{Cr}, \mathrm{S}$ 的分布图

图中右上筩为相应选区的位置图: A 区为黄 铁矿， B,D 区为石英, C区为孔雀石. 扫描范 围为 $154 \times 225 \mu \mathrm{m}$

个小山峰,结合物相试验资料, 可以认为其中的金是以极细小之包裹体形式存在的. 至于图 2 中 $\mathrm{S}$ 的分布所出现之小峰, 我们认为这可能是样品表面的微小不平整所致. 因为质子的穿透 性比电子大,弥散性比电子小, 因而质子探针能够提供试样一定深度的信息. 本次实验采用的 是质子激发 $\mathrm{X}$ 射线分析技术, $\mathrm{Fe}, \mathrm{S}$ 用的 $\mathrm{K}$ 线, $\mathrm{Au}$ 是 $\mathrm{L}$ 线, $\mathrm{Fe} \mathrm{K}_{\alpha}$ 线的能量近三倍于 $\mathrm{S}, \mathrm{Au}$ $\mathrm{L}$ 线的能量则更大,因而 $\mathrm{Au}, \mathrm{Fe}$ 之分布情况是试样表面和深部信息的综合反映, 相对而言, S 则主要是表面信息. 当然这尚有待于大量实验的进一步证实.

\section{参考文献}

[1] Fraser, D. G., Chem. Geol., 1990, 83(1/2): 35 37.

[2]朱节清、王媇民,岩矿测试，1991,(10): 262-266. 